\title{
Audit of screening for congenital hypothyroidism
}

\author{
P O D Pharoah, M P Madden
}

\begin{abstract}
The effectiveness and efficiency of the screening programme for congenital hypothyroidism in the Mersey region from 1983 to 1989 was examined by an analysis of laboratory, manual and computerised district records, case notes, and Hospital Activity Analysis data.
\end{abstract}

Births from 1 January 1983 to 31 December 1989 formed the study cohort and the proportion of live births screened, age when treatment was started, validity of the screening test, and the outcome of treatment were determined. In nine out of 10 districts coverage of the neonatal population by the screening programme was incomplete and there was failure to follow up infants who had not been screened. The sensitivity of the test was $\mathbf{9 7 \%}$ and the specificity was $99.9 \%$. In $10 \%$ of the positive cases treatment was delayed beyond 21 days, the latest was 26 days.

It is concluded that administrative deficiencies were predominantly responsible for the inefficiencies of the screening programme. The long term follow up of diagnosed cases should become part of the monitoring process.

(Arch Dis Child 1992;67:1073-6)

Congenital hypothyroidism is one of the main causes of mental impairment in children and is present in about 1:4000 births. ${ }^{1}$ Crucial to the management of congenital hypothyroidism is the institution of treatment as soon after birth as possible because the later treatment begins, the greater the degree of irreversible mental impairment. ${ }^{23}$ This underlines the potential benefits of an early neonatal screening programme. The advent of radioimmunoassay for thyroxine and later of thyroid stimulating hormone (TSH) in small samples of whole blood enabled routine screening to become a reality and programmes were introduced throughout Europe and North America with the aim of preventing mental impairment due to hypothyroidism.

The audit arrangements outlined in the government white paper, Working for Patients, ${ }^{4}$ have been universally welcomed and, currently, audit is being widely applied in almost all clinical disciplines. The Donnabedian model proposes that an audit may be made of structure, process, or outcome. ${ }^{5}$ Structural audit relates to the number and mix of staff and provision of facilities and equipment. Process audit is concerned with what is done by the staff with those facilities and equipment. Ultimately what really matters is outcome audit-that is in measures of mortality, morbidity, and patient satisfaction. It was decided to apply the Donnabedian model of audit to the screening for congenital hypothyroidism. In the Mersey region the screening programme for congenital hypothyroidism commenced in January 1983 and we report here an examination of its efficiency and effectiveness programme up to December 1989.

\section{Methods}

The topic areas for the audit were population coverage, the validity of the screening test, the age at which treatment was started, and the outcome as determined by the level of mental impairment.

\section{COVERAGE}

Notification of all births to the district health authority is a statutory requirement. The birth notification register that is compiled from the statutory notifications was used to obtain the denominator population in order to determine coverage.

In those districts that had a child health computer system (CHCS), the birth notification initiated the computerised child health record. The results of the screening test is also entered on to the computer so that the names, addresses, and dates of birth of those children who were not screened could be obtained. The districts may also use a manually recorded system.

Two problems were encountered when assessing the coverage of the programme. The entry of the child into the birth notification system is determined by the district of residence of the mother when the child is born. The birth, however, may take place in a different district. In these cases, if the midwife omits to enter the district of residence on the card containing the blood spot to be screened, the result will be notified to the wrong district. This may lead to an over enumeration in some districts and an under enumeration in others. The second problem also leads to over enumeration and arises when a repeat specimen has to be taken from the child because the first was technically unsatisfactory.

Two districts had neither a computerised nor a manual system for linking the birth notification with the result of the screening test. Therefore, it is not possible to determine, for these districts, the coverage rate nor is it possible to follow up those children who had been missed in the initial screening process.

Two districts had a manually operated system only. In one of these it was the responsibility of 
one clerk who ensured that any child with no test result was brought to the attention of the health visitor and followed up. The other obtained a list of names only from the birth notification register against which the test result was entered. As there was neither an address nor date of birth on the list, it was not possible to validate completeness of coverage against the laboratory records.

The remaining six districts all had a computerised child health record system which allowed a validation of the completeness of coverage.

For two years (1988 and 1989) of the study period a validation was carried out. A single regional laboratory performed all the screening tests and for those children who, on the CHCS were recorded as not having been screened, the laboratory records were inspected to confirm the observation. A search of the laboratory records of the adjacent North Western region

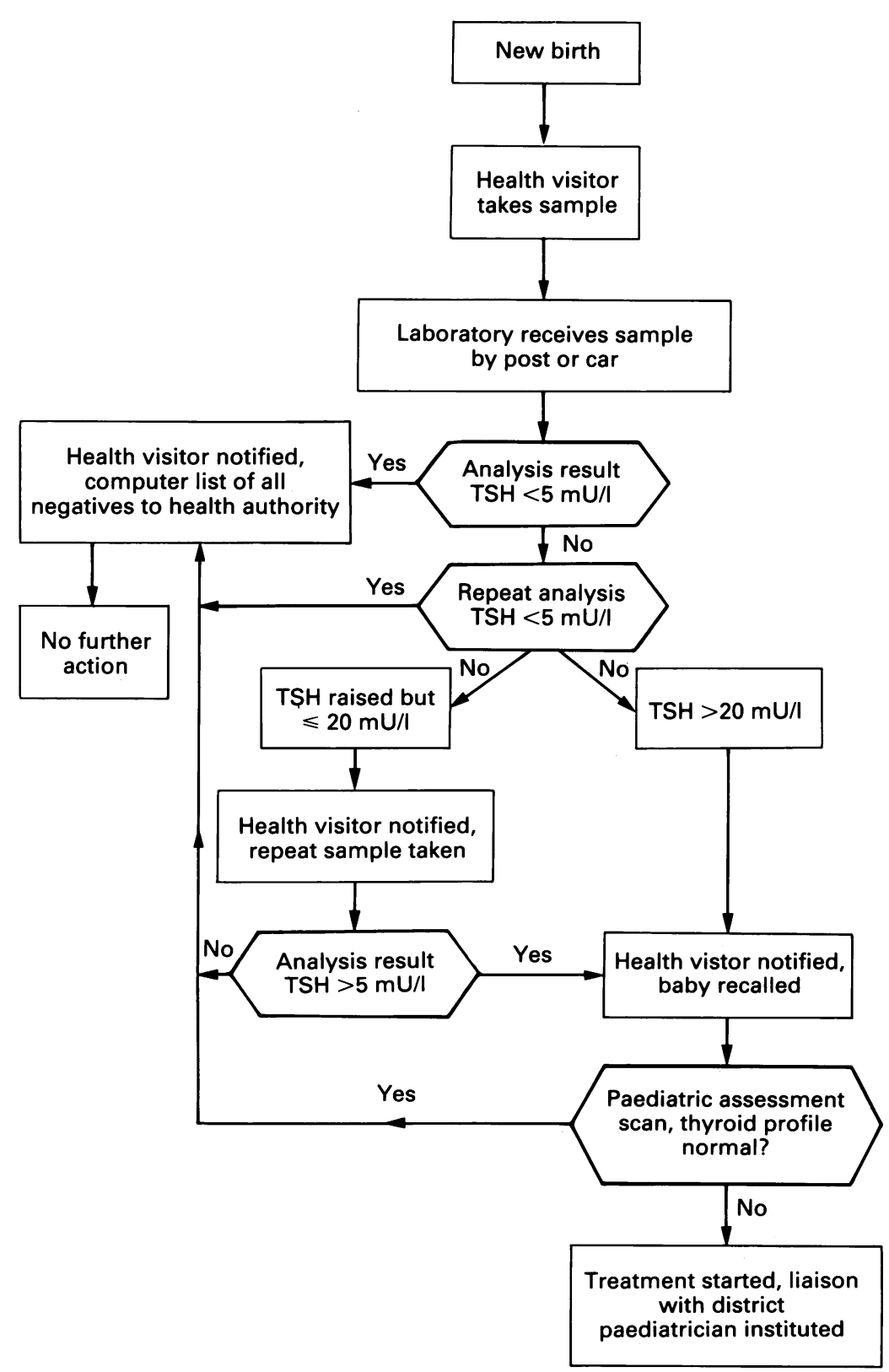

Flow chart of screening procedures. was also made for those children who were normally residents of the Mersey region but may have been born and screened in the adjacent region. Thus, for the 10 districts in Mersey region, it was possible to determine the proportion of children for whom there was no record of any screening test for congenital hypothyroidism in six districts with a computerised system and in one of the two districts with a manual system.

\section{VALIDITY OF THE SCREENING TEST}

There are two components to the validity of a test: the sensitivity and the specificity. Sensitivity is determined by the proportion of cases that are correctly identified by the test and is affected by the number of cases that are missed, that is, the false negatives. Specificity is a measure of those without the disease who are correctly identified and is affected by the false positives.

The false negatives were sought using several different sources:

(i) Each consultant paediatrician in the region was asked to identify any child known to them, diagnosed as clinically hypothyroid, who was missed by the screening programme.

(ii) The Hospital Activity Analysis (HAA) information system for both Mersey and North Western regions was scanned for all children admitted with a diagnosis of hypothyroidism and the names checked against the list of those diagnosed by the screening programme.

(iii) In the regional children's hospital the biochemistry department records were checked for any children having thyroid function tests, prescriptions for thyroid hormone replacement therapy were sought from pharmacy records, and the radiology department's records of any child having a thyroid scan were examined.

The false positives were obtained from the regional laboratory and were those children who were recalled for confirmative diagnostic tests after an abnormal screening result but were found not to have the disease.

\section{AGE WHEN TREATMENT WAS STARTED}

The aim of the screening programme is to have all blood specimens in the laboratory by the time the baby is 14 days old and to have all positive cases on treatment by 21 days of age.

A flow chart of the procedures from the day of birth to the time that treatment is started is shown in the figure. Reasons for and the length of any delay in instituting treatment were assessed by determining the age of the infant when the blood spot was received by the laboratory for analysis, by the age of the infant when the paediatrician was notified of the test result, and by an examination of the hospital records of all cases diagnosed as having congenital hypothyroidism and noting the age at which treatment was started.

OUTCOME OF TREATMENT

As part of a national study all cases identified by the screening programme are notified to the 
Medical Research Council under whose auspices a register is maintained. For each case, a control matched for age, sex, social class, and language background is selected. When aged 5 years the cases and controls are assessed using the Wechsler preschool primary scale of intelligence (WPPSI). However, only 11 case-control pairs within the national data set come from Mersey region and outcome measures based on such small numbers were not considered appropriate.

\section{Results}

COVERAGE

In seven out of the 10 districts in the region it was possible to determine the population covered. During the years 1988 and 1989 there were 38216 births in these districts of whom $37235(97 \cdot 4 \%)$ were tested. Within each district the population covered ranged from $96 \cdot 2-100 \%$. Only one district succeeded in attaining $100 \%$ coverage; it used a manually operated system and a clerk had sole responsibility for maintaining it. In only nine cases was the failure of screening attributable to parental refusal. For three districts completeness of coverage could not be ascertained.

\section{VALIDITY OF THE SCREENING TEST}

From the screening programme, 60 infants were confirmed as having congenital hypothyroidism. In addition there were two false negatives. One infant, resident within but born outside the region, with multiple congenital anomalies, was admitted because of a severe cardiac anomaly when aged 115 days and found to be hypothyroid. This infant subsequently died. The second case was picked up through the HAA data set as having been admitted for hypothyroidism, although the initial screening result for TSH had been within normal limits. The case records showed that she had been admitted with a hepatic haemangioma at which time a raised TSH but normal thyroxine concentration and bone age were found. A scan showed an enlarged thyroid and treatment was started at 56 days of age.

The sensitivity may be said to be $60 / 62$ $(97 \%)$, although one of the missed cases was essentially a failure of the screening programme rather than an invalid test. There were 162 false positives who were recalled for retesting as a result of a raised initial TSH. Two of these cases who were recalled for further testing were found to have normal thyroid hormone concentrations despite a persistently raised TSH and were considered clinically euthyroid. The specificity was therefore $193003 / 193165(99 \cdot 9 \%)$.

Delay in blood spot reaching the laboratory*

\begin{tabular}{|c|c|c|c|c|c|}
\hline & 1983 & 1984 & 1985 & 1986 & 1988 \\
\hline $\begin{array}{l}\text { Proportion reaching laboratory after } \\
14 \text { days of age (\%) } \\
\text { Proportion reaching laboratory after }\end{array}$ & $12 \cdot 4$ & $11 \cdot 1$ & $10 \cdot 2$ & $7 \cdot 2$ & $9 \cdot 8$ \\
\hline 21 days of age $(\%)$ & $1 \cdot 8$ & 1.5 & $1 \cdot 4$ & $1 \cdot 2$ & $2 \cdot 2$ \\
\hline
\end{tabular}

${ }^{*}$ Records not available for 1987 owing to postal strike affecting receipt of blood spots by the laboratory.
AGE WHEN TREATMENT WAS STARTED

The stated policy aim of the programme is to have all the blood spots for testing in the laboratory by the time the child is 14 days old. The proportion of children for whom this objective was attained and the proportion for whom the delay was over 21 days is shown in the table. There is a trend towards a decrease in the delay over the period of study but much of the improvement was attributable to one district which changed from a postal to a daily van delivery service. In $75 \%$ of all infants (whether with a normal or abnormal test result) the test result was available to the consultant paediatrician within 21 days.

Of the 60 cases diagnosed hypothyroid by the screening programme, in $90 \%$ treatment was started within 21 days of birth and the latest treatment was started was 26 days after birth.

OUTCOME OF TREATMENT

Because the WPPSI measure was applied to the children when aged 5 years, only those children diagnosed in the earliest period of this study could be included. As there were only 11 such case-control pairs in Mersey region, it was felt inappropriate to present the outcome assessment based on these 11 pairs, but such assessment should await the analysis of the national data set.

\section{Discussion}

The 62 cases of congenital hypothyroidism arose from a population of 228289 livebirths in the Mersey region from 1983-9 giving a birth prevalence of $1: 3770$. This level of prevalence is similar to the 1:3980 found from 36 centres in 12 European countries and the 1:4200 reported from the USA, ${ }^{1}$ which suggests that it is unlikely that a significant number of cases, other than the known false negatives, were missed.

The major failures of the screening programme in the Mersey region are of an administrative nature. Two districts, having neither a computerised nor a manual system of linking the screening result with the birth notification, could not determine what proportion of the newborn population was covered by the screening programme, neither could they organise any follow up of children who had not been tested. Even those districts with a CHCS did not carry out these procedures that ought to be routine in the regular evaluation of any screening programme. Many of the problems of both over and under enumeration due to cross boundary flows of births could be nullified by the simple expedient of requiring that the area of residence of every child is recorded on the card containing the blood spot sent to the laboratory.

The failure to follow up those children who were not tested is also easily remediable and should be made routine. Based on the numbers found in the validation exercise there is likely to be one case missed approximately every five years and this may prove hard to defend if litigation ensues. 
The success of the screening programme is ultimately judged by whether or not mental impairment has been prevented in children with congenital hypothyroidism. Follow up studies of hypothyroid infants diagnosed by neonatal screening show normal or near normal intelligence quotients and/or developmental scores when compared with controls. ${ }^{6} 7$ However, a note of caution has been sounded: severe fetal hypothyroidism may not be fully compensated by the placental transfer of maternal hormone so that, even at birth, some degree of irreversible mental deficit may be present. This is most likely if there are other stigmata of hypothyroidism, for example delayed bone maturation, present at birth. ${ }^{8-10}$ In the national Medical Research Council cohort, infants who were severely hypothyroid at birth, with a plasma thyroxine value of $30 \mathrm{nmol} / \mathrm{l}$ or less, had a significantly higher incidence of prolonged jaundice, feeding difficulties, lethargy, umblical hernia, and macroglossia and showed more severe delay of bone maturation on a knee radiograph. ${ }^{11}$

A definitive answer on the outcome of screening for mental impairment must await the results of the national study, nevertheless, regional screening programmes should be moni- toring various process measures as part of the audit cycle.

1 Delange F, Beckers C, Hofer R, Konig MD, Monaco F, Varrone S. Progress report on neonatal screening for congenital hypothyroidism in Europe. In: Burrow GN, Dussault JH, eds. Neonatal thyroid screening. New York: Raven Press, 1980:107-31.

2 Klein AH, Meltzer S, Kenney FH. Improved prognosis in congenital hypothyroidism treated before aged 3 months. congenital hypothyroidism

3 Raiti S, Newns GA. Cretinism; early diagnosis and its relation to mental prognosis. Arch Dis Child 1971;46:692-5.

4 Department of Health. Working for patients. London: HMSO, 1989. (Cmd555.)

5 Donnabedian A. Evaluating the quality of medical care: a concept in search of a definition. Milbank Memorial Fund Quarterly 1966;44:166-203.

6 New England Congenital Hypothyroidism Collaborative. Neonatal hypothyroidism screening: status of patients at 6 years of age. F Pediatr 1985;107:915-9.

7 Glorieux J, Dussault JH, Morisette J, Desjardines J, Letarte $M D$, Guyda $H$. Follow up at ages 5 and 7 years on menta development in children with hypothyroidism detected by Quebec screening. F Pediatr 1985;107:913-5.

8 New England Congenital Hypothyroidism Collaborative. Effects of neonatal screening for hypothyroidism: prevention of mental retardation by treatment before clinical manifestations. Lancet 1981;ii: 1095-8.

9 Murphy GH, Hulse JA, Smith I, Grant DB. Congenital hypothyroidism: physiological and psychological factors in
early development. $\mathcal{F}$ Child Psychol Psychiatry 1990;31: early de $711-25$.

10 Rovet J, Ehrlich R, Sorbara D. Intellectual outcome in children with fetal hypothyroidism. $\mathcal{F}$ Pediatr 1987;110 $700-4$.

11 Grant DB, Smith I, Fuggle PW, Tokar S, Chapple J. Congenital hypothyroidism detected by neonatal screening: relationship between biochemical severity and early clinica features. Arch Dis Child 1992;67:87-90. 